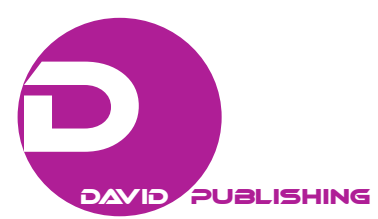

\title{
Principal Leadership Styles in Bedouin Secondary School in the Negev
}

\author{
Salih Alasad \\ West University of Timisoara, Timisoara, Romania
}

\begin{abstract}
The aim of the research is to explore leadership styles applied by the principals of the secondary schools in Negev in south of Israel, as viewed by the teachers and it's aimed to find out whether factors such as settlement, school location, and gender of teacher may change principal leadership style in the secondary school in Negev. The research relies on the theory of full range leadership model. Design/methodology/approach questionnaires assessing the variables of interest were completed by 306 teachers in 22 Bedouin secondary schools in Negev. Statistical analysis that had been made to the data included mean, standard division, and $t$-test. The results of the research indicated that the teacher characteristic affected the principal leadership style. Principal changed his/her behavior according to the teacher characteristic. The principal in temporary settlements is more transformative than principal in permanent settlement. Bedouin principal also is more transactional with non-local teachers than with local teachers and he is less laissez-faire with female than males.
\end{abstract}

Keywords: Bedouin, leadership styles, transformational leadership

\section{Introduction}

Leadership is perhaps one of the most important aspects of management (Weihrich, Cannice, \& Koontz, 2008); this is because leadership is a major factor which contributes immensely to the general wellbeing of organizations and nations (Robbins \& Coulter, 2007). Great nations like the United State of America, Britain, France, and India are some of the most prominent nations in the world today on the wings of effective leadership (Nordin \& Wan, 2012). This is because leaders in organizations and nations make things happen.

Successful, effective leaders have conquered achievement goals for their schools because they took care of the people accountable for learning "the teachers" and all involved in the school performed at higher levels. The goal has been to have successful schools encompass the leader and the individuals involved. The principal must also be honest about personal strengths and weaknesses and possess willingness to compromise when necessary. The effective principal should combine strategies to improve teaching and learning while compassionately nurturing those employed in the school (Abwalla, 2014; Kipkemboi, Henry, \& Jemiryott, 2014; Drake \& Roe, 1986; Littleford, 2007).

The education system in Bedouin sector is very complex and teaching workforce in the Bedouin educational system in Negev has its unique characteristics, as the Bedouin community is a traditional one. It is

Salih Alasad, Ph.D., Management and Education, Management Department, West University of Timisoara, Timisoara, Romania.

Correspondence concerning this article should be addressed to Salih Alasad, P.O. Box 161, Lakia 8499100, Israel. 
very important to explore the principal behavior in this complex condition from the point of view of the teachers. Understanding this issue can help principals to improve teachers practice. This paper tests the leadership styles applied by the principals of the secondary schools in Negev in south of Israel, as viewed by the teachers. It's examined whether factors such as settlement, school location, and gender of the teacher change the principal leadership style in the secondary school in Negev. It is very important to use appropriate leadership style to every teacher and to nurture compassionately those employed in the school; that will support teachers to perform the tasks assigned to them.

\section{Literature Review_Leadership Style}

\section{Transformational Leadership}

A transformational leader is a person who stimulates and inspires (transform) followers to achieve extraordinary outcomes (Bass \& Avolio, 1994). He/she pays attention to the concern and developmental needs of individual followers; they change followers' awareness of issues by helping them look at old problems in a new way, and they are able to arouse, excite, and inspire followers to put out extra effort to achieve group goals. Transformational leadership theory is all about leadership that creates positive change in the followers whereby they take care of each other's interests and act in the interests of the group as a whole (Warrilow, 2013).

\section{Transactional Leadership}

Also known as managerial leadership, transactional leadership focuses on the role of supervision, organization, and group performance; transactional leadership is a style of leadership in which the leader promotes compliance of his followers through both rewards and punishments. Unlike transformational leadership, leaders using the transactional approach are not looking for changing the future; they are looking for merely keeping things with the same. These leaders pay attention to followers' work in order to find faults and deviations. This type of leadership is effective in crisis and emergency situations, as well as when projects need to be carried out in a specific fashion. Transactional leaders are effective in getting specific tasks completed by managing each portion individually (Odumeru \& Ifeanyi, 2013).

Transactional leaders are concerned with processes rather than forward-thinking ideas. These types of leaders focus on contingent reward (also known as contingent positive reinforcement) or contingent penalization (also known as contingent negative reinforcement (Hargis, Wyatt, \& Piotrowski, 2001)).

\section{"Sit and Wait" Leadership Style}

The most prominent characteristic of this leader's behavior is avoidance from taking a stand, from decisions making, and actually from any action. This non-active leadership reflects each attempt not to affect. The subordinates of this leader don't receive guidance or support, and typically show indifference and carelessness, and will tend to focus on achieving their personal goals, even if they are in conflict with the objectives of the organization or the group (Bass, 1985).

\section{The Principal in Bedouin Education System}

The school is considered by the society as the property of a particular family in the village, especially when the principal or most of the teachers are from one tribe. The hierarchical relationship between employees of the school system is rigid and it limits the initiative of the principal, who is supposed to be a leading figure 
when the school education process is vulnerable and unable to withstand external pressures, tensions in society that penetrate it easily and affect its atmosphere. The competition between the clans for a local power system finds its way to schools and affects the relationships between the teachers and the management. The concentration of the clans created division of teachers based on clans in a same school; therefore a conflict between clans outside the school penetrates the walls and increases the tensions between the different groups. And further research found that the main factor that influences the organizational climate in Bedouin schools of Israel is the principal leadership style. Bedouin principals usually demonstrate the power and illustrate discipline of work, innovation, and involvement (Alkshaala, 2008; Abu-Saad, 2010).

\section{Characteristics of the Teaching Force in the Bedouin Sector in the Negev}

The teaching workforce in the Bedouin educational system in Negev has its unique characteristics, as the Bedouin community is a traditional one. In the recent years, the Bedouin community passed through many changes in the workforce in teaching, such as:

\section{Women in the Bedouin Education System in Negev}

An increase occurred in the percentage of the Bedouin female teachers, as well as the percentage of the educated Bedouin females, because the youth are now more and more tending to get married with the educated girls. As a result, the status of the educated woman was promoted, even within the families living according to the traditional lifestyle.

The number of the girls who complete their secondary education is noticeably high. Nowadays, we find that most of the girls complete their secondary education. Thereby the rate of the teachers is rapidly increasing among the total teaching workforce in the Bedouin milieu in Negev (Barnea, 1991; Abu-Saad, 2010).

\section{North and Local Teachers}

There are large numbers of teachers in the Bedouin education system in Negev, both male and female teachers coming from the north and center of the country. There is a wide increase in the rate of the local teachers, because there is a need for the teachers of the north, especially in the major subjects, such as English language, mathematics, and science. The rate of the teachers coming from the north is three doubles as much those coming from the local milieus. On the other hand, the rate of the female teachers coming from the north milieus overweighs the number of female teachers from the local workforce. Those female teachers have their influence in the local community in terms of upgrading the status of the woman in the Bedouin education system.

In this concern, certain researchers claim that there are struggles among the teachers of the north and those of the local community, because of the differences in culture, habits, and traditions (Barnea, 1991; Abu-Saad, 2010).

\section{Teachers in Both Sections of the Education System (With Permanent and Temporary Settlement)}

The established phenomenon in the country, and outside the country, is that the areas with good and developed settlement facility will obtain good education conditions, and attract teachers with good academic levels. On the other hand, areas with poor settlement conditions will have less experienced teachers who are changeable even within short intervals.

Even in the Bedouin milieu, we find two types of settlement areas, with different settlement conditions. In this regard, two thirds of the Bedouin residents in Negev moved to live in permanent settlements, where the public institutions and schools are built according to advanced and high standards, which include good 
infrastructures, such as electricity, public parks, and streets.

More than one third of the population lives in temporary settlements lacking infrastructures such as water, streets, and electricity. People here are still living in houses made of zinc and in tents. In addition, the educational institutions and schools are also in temporary buildings. However, in the recent years, many villages were recognized and school and public institutions were built in these areas according to the modern styles (Barnea, 1991; Abu-Saad, 2010).

To sum, many changes took place in the workforce in the Bedouin milieu. Firstly, the steady increase in the number of the female teachers; secondly, the Bedouin education is still linked to the teaching forces coming from outside Negev, but the rate of the local teachers is rapidly increasing; thirdly, more than one third of the Bedouin population is still living in settlements lacking the infrastructures. In the recent years, however, a number of the unrecognized villages had been recognized, and modern schools were built there.

\section{Research Methods}

Results of the study were based on a wide sample which included 306 teachers from 22 schools in permanent towns and temporary settlements. The aim of this study is to explore the leadership styles of the secondary school principals in the Negev. And it is also aimed to find out whether factors such as settlement, school location, and gender of the teacher may change the leadership style of the school principals in Negev. This research was carried out in all secondary schools in the Bedouin sector in Negev in south Israel as a part of $\mathrm{PhD}$ study. In this study, the amended short form of the questionnaire (MLQ-X5, Multi-Factor Leadership) was employed, as it most fits to the study sample, which was applied in previous study in Israel in the northern part of the country, in both Arab and Jewish elementary schools (Kurland, 2006).

\section{Research Results}

The research took place in Bedouin education sector in the Negev in south Israel and the questionnaires assessing the variables of interest were completed by 306 teachers in 22 Bedouin secondary schools in Negev. Statistical analysis that had been made to the data included mean, standard division, and $t$-test.

This study shows important orientations, mainly, the applicable leadership style with the principals of the Bedouin schools in Negev is the transformational leadership and factors such as type of settlement, teacher's place of residence and gender changed the principal leadership style.

\section{Background Variables}

306 male and female teachers participated in this study. The background variables of the participation in this study are: official local status of the town-permanent settlement (78.8\%) and temporary settlement (21.2\%); gender-male (57.2\%) and female (42.8\%); academic degree-BA (65.4\%), MA (29.7\%), Ph.D. (1.6\%), and other (3.3\%); original domicile place-south of the country (66.6\%) and north of the country (33.4\%); age-less than 30 (43.8\%), 30-39 (35.6\%), 40-49 (13.4\%), and more than 50 years (7.2\%); seniority in education-less than 10 years (58.2\%), 10-20 (30.7\%), and more than 30 years (11.1\%).

\section{Distribution of the Leadership Over the Bedouin Secondary Schools}

Table 1 shows that teachers reported that the transformational leadership style is the one that characterizes the school principals in Negev at a high level (average 3.72). The lowest degree was given to the laissez faire leadership style (2.10), and the transactional leadership style came with a medium degree (3.22). 
Table 1

Distribution of the Leadership Styles

\begin{tabular}{lll}
\hline Leadership style & M & \\
\hline Transformational leadership & 3.72 & 0.65 \\
Transactional leadership & 3.22 & 0.74 \\
Laissez faire leadership & 2.10 & 0.74 \\
\hline
\end{tabular}

Based on the standard deviation (SD) and t-test analyses, we find differences in the teachers' reports about leadership styles which were used by principal in their schools. Thus, the teachers' reports about the leadership styles were tested according to many factors such as the type of settlement where the school is located, original domicile place of teachers, and the teachers' gender. The aim of this test was to find how teachers' characteristics influence the principal leadership style as the teachers' report.

\section{Distribution of the Leadership Style by the Type of the Settlement (Where the School Is Located)}

Table 2 shows that the teachers reported that the transformational leadership style is the one that characterizes the principals in the Bedouin secondary schools in high degree by two grades.

Table 2

Distribution of the Leadership Styles by Location

\begin{tabular}{lllllll}
\hline Leadership style & \multicolumn{2}{c}{ Temporary settlement } & \multicolumn{2}{c}{ Permanent settlement } & Test statistic \\
\hline & SD & M & SD & M & & \\
\hline Transformational leadership & 0.64 & 3.89 & 0.63 & 3.66 & 2.549 & 0.011 \\
Transactional leadership & 0.79 & 3.2 & 0.72 & 3.22 & 0.132 & 0.895 \\
Laissez faire leadership & 0.73 & 2.01 & 0.74 & 2.12 & -1.068 & 0.286 \\
\hline
\end{tabular}

The highest grade that has been reported was 3.89 (the temporary settlement), followed by 3.66 from the permanent settlement (town). However, the data indicated that there is a significant difference in teachers' reports between the two types of the settlements in Bedouin secondary schools. The transformational leadership styles characterize the principal in temporary settlement in a higher degree than the principal in the permanent settlement. $T$-test shows a significant difference in the teachers' report between temporary settlements teachers and permanent settlements teachers in relation to transformational leadership. Teachers in temporary settlement reported that principal is more transformative than teachers in permanent settlement; this is due to differences in education conditions in the two types of the settlements.

The data also show that the laissez faire leadership style characterizes all of the principals at a very low degree as follows: Temporary settlement (2.01) and Permanent town settlement (2.12), while the transactional leadership style characterizes the school principals at both types of settlement at medium degrees. The teachers in the two types of settlement agreed about this type of leadership and they reported the same degree: (3.2) was temporary settlement and (3.22) was permanent town. $T$-test that has been made does not indicate differences between the teachers' reports about both leadership styles (transactional and laissez-faire leadership) in the two types of Bedouin settlements (temporary and permanent).

\section{Leadership Style by the Teachers’ Place of Residence (North/Local)}

Table 3 shows that the local and nonlocal teachers reported that the transformational leadership is the one that characterizes the school principals in the Bedouin secondary schools in both types of settlements at a higher degree as follows: non-local teachers (3.8) and local teachers (3.7). 
Table 3

Leadership Styles by Teacher Settlement Area

\begin{tabular}{lllllll}
\hline Leadership style & \multicolumn{2}{c}{ Non-local teacher (north) } & & Local teachers & Test statistic & $P$-value \\
\hline & SD & M & SD & M & & \\
\hline Transformational leadership & 0.65 & 3.8 & 0.64 & 3.7 & -1.057 & 0.291 \\
Transactional leadership & 0.71 & 3.4 & 0.74 & 3.1 & -2.597 & 0.010 \\
Laissez faire leadership & 0.78 & 2.0 & 0.71 & 2.1 & 1.145 & 0.253 \\
\hline
\end{tabular}

However, there are some differences between local and non-local teachers' reports. In this concern, the results show that the transformational leadership style characterizes the principal in high degree. The results show also that the non-local school teachers have higher grades than the local school teachers. Furthermore, the laissez faire leadership characterizes the principal at a very low degree, (as per non-local school teachers 2.0, local school teachers at the rate of 2.1). $T$-test which has been made indicates that these differences between non-local and local teachers are not significant according to these two types of leadership style, meaning that there is almost a coincidence between the local and non-local teachers.

While the transactional leadership style characterizes the principal by the perspective of non-local teachers and the local teachers at medium degree. T-test indicated that there are significant differences between non-local and local teachers' reports. Non-local teachers reported that transactional leadership style characterized the principal in higher degree than the local teachers (non-local 3.4 and local 3.1); this is due to the distance from schools, the Bedouins customs, and traditions.

\section{Leadership Style by the Gender (Males/Females)}

In the traditional and masculine Bedouin community the male is the dominant, but in the case of relationship with female his actions and relationship are controlled by the Bedouin habits and traditions. Any inappropriate behavior with a woman can result in a harsh response from her tribe and punishments under Bedouin law.

Table 4 shows that the teachers reported that the transformational leadership style is the one that characterizes the principals in Bedouin secondary schools at higher degrees (male teachers 3.7 and female teachers 3.7).

Table 4

Leadership Styles by Gender

\begin{tabular}{lllllll}
\hline Leadership style & & Female & & Male & Test statistic & $p$-value \\
\hline & SD & M & SD & M & & \\
\hline Transformational leadership & 0.67 & 3.7 & 0.62 & 3.7 & 0.068 & 0.946 \\
Transactional leadership & 0.71 & 3.2 & 0.76 & 3.2 & -0.105 & 0.916 \\
Laissez faire leadership & 0.47 & 2.0 & 0.42 & 2.2 & 2.363 & 0.019 \\
\hline
\end{tabular}

Meanwhile, there is a complete agreement between male and female teachers that transformational leadership is the one that characterizes the principals of the Bedouin secondary schools at higher degrees (female teachers 3.7 and male teachers 3.7), and there is also a complete agreement between the male and female teachers that transactional leadership style characterizes the principals at medium degrees (male teachers 3.2 and female teachers 3.2). While male and female teachers are not in agreement in concern to the laissez-faire leadership. Male reported that principal is more laissez-faire than female (male 2.2 and female 2.0). 
This difference between male and females teachers is significant. This difference is indicative of the strong influence of the Bedouin traditions on the principal's behavior toward female teachers, taking it into account that the habits and traditions of the Bedouin society required more principal's cares for female teachers.

In general, the teachers reported that the leadership style followed by the school principal is the transformational leadership style, followed by transactional leadership style and the lowest level is the laissez-faire leadership. The data indicate also that there are significant differences between teachers' perspective to leadership styles according to the type of settlement, the teachers' place of residence, and the teachers' gender.

\section{Discussion}

This study examines how teachers' characteristics influence the leadership styles applied by the principals of the secondary schools in Negev in south of Israel, as viewed by the teachers. It also aimed to find out whether factors such as settlement, school location, and gender of the teachers may change in his/her report about the applicable leadership style by the school principals in Negev.

The data indicate that the dominant leadership style applied by principal in Bedouin secondary school is transformational leadership. The transformational leader is a person who stimulates and inspires (transforms) followers to achieve extraordinary outcomes. They pay attention to the concern and developmental needs of individual followers; they change followers' awareness of issues by helping them look at old problems in a new way; and they are able to arouse, excite, and inspire followers to put out extra effort to achieve group goals. Transformational leadership theory is all about leadership that creates positive change in the followers whereby they take care of each other's interests and act in the interests of the group as a whole (Hargis, Wyatt, \& Piotrowski, 2001).

As far as the type of settlement where the school located is concerned, the data indicated differences in the teachers' reports about principal leadership style in temporary and permanent settlements. In this concern, the research finds that the transformational leadership style is the one that characterizes temporary school principal at a higher degree. Teachers in temporary schools reported that principal is more transformative than teachers in permanent settlement. This clearly interprets the influence of the well-known phenomenon, both inside and outside the country, that the principal in good and developed settlement areas obtains good education conditions, and attracts teachers of higher academic degrees. On the other hand, areas with poor settlement conditions attract less experienced teachers, who are changed at close intervals for their principal. Therefore the principal needs to be more transformative since teachers had been changed permanently; every year principal has new teachers, so the principal's support, direction, and guidance are necessary for new teachers to be integrated into their new schools.

There is a strong link in the Bedouin education system in Negev with the male and female teachers coming from the center and north parts of the country, in spite of the large increase in the number of the local teachers. As noted in literature, the rates of the academics of the teachers coming from the northern parts are more than three doubles as much of the academics in the local teachers. The same is true for the rates of the female teachers from the north, which overweighs those of the local female teachers. Nonetheless, there is an influence on the local community in raising the status of the woman in the education system in the Bedouin milieu. Still, there are differences between the teachers of the north and the local community because of the differences in the culture, habits, and traditions (Barnea, 1991; Abu-Saad, 2010). However, the local and non-local teachers 
reported that the transactional leadership style characterizes the principal in a medium degree, while there is a significant difference between non-local and local teachers' report about the transactional leadership. The non-local teachers reported that the transactional style characterizes their principal in a higher degree than the local teacher's report, which probably is connected to difference between the customs and traditions and also caused by the difference in distance from school. The teachers that come from north pay a lot of money for travelling and for renting a house; therefore it is very important for them to earn financial rewards to cover their expenses. From the social side, the relationship between principal and local teachers is controlled by the Bedouin law while the relationship with the teachers from north controlled by regulation and laws of the western education system. The Bedouin teachers are more protected than teacher from north due to the habits and Bedouin law; therefore it is very difficult for principal to use transactional leadership (especially punishment) with Bedouin teachers while he can use this leadership style with non-local teachers, because in this case he is free from Bedouin law and he acts according to regulation and laws of the western education system.

Moreover, the gender of the teacher influences the principal leadership style to a wide extent according to teachers reporting. The male teachers reported the laissez-faire leadership as the one that characterizes the school principals in the Bedouin secondary school at a higher degree than the female teachers' reports. This means that principal cares about female teachers more than males. It seems that the reason for these differences is the customs and traditions in the Bedouin community. Bedouin women also experience gender discrimination perpetuated by two cultural codes that govern Bedouin life: the sexual code and the collective code. The Bedouin sexual code affects every aspect of a girl's upbringing, from childhood to marriage. Under the sexual code, perceptions of honor and shame dictate behavior. This sexuality also makes the woman important, who is highly protected by Bedouin traditional law and any offense against a woman may lead to revenge by her male kin (Abu-Rabia-Queder, 2007). These codes, probably affect the principal behavior towards female teachers. In this case the principal acted as male kin for female teachers and he protected and supported them in their work more than male teachers.

\section{Conclusions}

The results of this research indicate the teachers' characterises affected the principal leadership style. The principal changed his behaviour according to the teachers' characteristics. Factors such as types of settlement, the teachers' place of residence, and the teachers' gender change the principal's behavior and leadership style. The principal in temporary settlements is more transformative than principal in permanent settlement. Bedouin principal also is more transactional with non-local teachers than with local teachers and less laissez-faire with female than males. This probably was affected by the Bedouin culture and differences between in distance from school and dualism in regulation and laws in the Bedouin education system, Bedouin regulation system from one side and western regulation and laws from other side.

\section{References}

Abu-Rabia-Queder, S. (2007). The activism of Bedouin women: Social and political resistance. Polity and Identities, 7(2), 67-84. Abu-Saad, I. (2010). Arabs of the Naqab: Past, present and future challenges. Beer-Sheva: Ben-Gurion University of the Negev. Abwalla, J. O. (2014). The principals' leadership styles and teachers performance general secondary schools of Gambella in regional state. Jimma, Ethiopia: Jimma University.

Alkshaala, B. (2008). Nature of the relationship between teacher and student in the Bedouin sector. Gameah, 12, 190-210. Bakah Alqrbea. 
Barnea, D. (1991). Teachers in Bedouin education in the Negev. Booklet, 22, 15-29. The symposium on Bedouin memory of Yitzhak Netzer, Sde Boker.

Bass, B. M., \& Avolio, B. J. (1994). Improving organizational effectiveness through the trans-formational leadership. NY: Sage.

Bass, B. M. (1985). Model of transformational leadership. In T. F. Mech and G. B. McCabe (Eds.), Leadership and academic librarians (pp. 66-82). Westport, CT: Greenwood.

Drake, T. L., \& Roe, W. H. (1986). The principalship (3rd ed.). New York: Macmillan Publishing Company.

Hargis, M. B., Wyatt, J. D., \& Piotrowski, C. (2001). Developing leaders: Examining the role of transactional and transformational leadership across contexts business. Organization Development Journal, 29(3), 51-66.

Kipkemboi, J. K., Henry, K., \& Jemiryott, S. (2014). Relationship between principals’ leadership styles and secondary school teachers' job satisfaction in Nandi South District, Kenya. Journal of Education and Human Development, 3(2), $493-509$.

Kurland, H. (2006). Organizational learning as a result of the leadership and vision, and its contribution to the investment of effort, satisfaction from teachers and obtain educational elementary schools. Israel: University of Haifa.

Littleford, A. R. (2007). Principal leadership and its perceived influence on teacher morale in elementary schools. Electronic Theses and Dissertations, East Tennessee State University, U.S.A.

Nordin, Y. G., \& Wan, H. S. (2012). Principal leadership styles in high-academic performance of selected secondary schools in Kelantan Darulnaim. International Journal of Independent Research, 1(2), 57-67.

Odumeru, J., \& Ifeanyi, G. O. (2013). Transformational vs. transactional leadership theories: Evidence in literature. International Review of Management and Business Research, 2(2), 355-361.

Robbins, S. P., \& Coulter, M. (2007). Management (9th ed.). London: Prentice-Hall.

Warrilow, S. (2013). Transformational leadership theory-The 4 key components in leading change \& managing change. Retrieved from http://EzineArticles.com/?expert=Stephen_Warrilow

Weihrich, H., Cannice, M. V., \& Koontz, H. (2008). Management (12th ed.). New Delhi: McGraw Hill. 